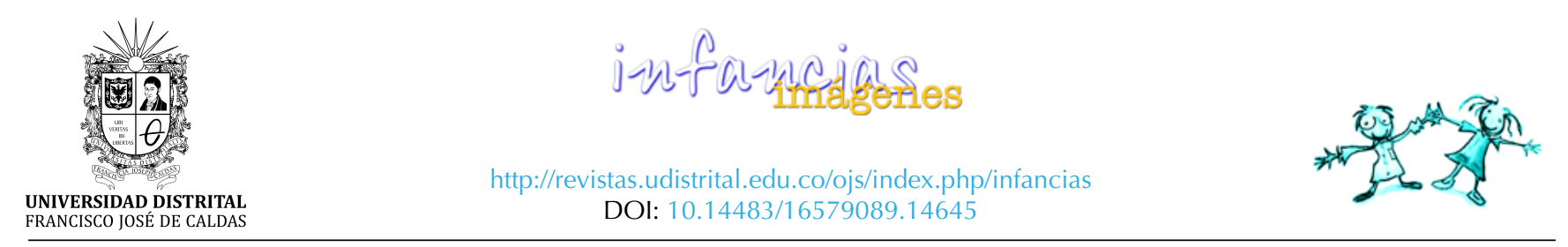

IMÁGENES DE INVESTIGACIÓN

\title{
El escuchar de los maestros a partir de la entrevista conversacional*
}

\section{The listening of the teachers from the conversational interview}

\author{
Gloria Rojas Álvarez
}

\author{
Para citar este artículo: Rojas, G. (2020). El escuchar de los \\ maestros a partir de la entrevista conversacional. Infancias \\ Imágenes, 19(1), 58-69
}

\section{Resumen}

Desde una investigación de corte cualitativo sobre la necesidad de indagación alrededor del tema de fundamentada en planos conceptuales como la el silencio, aspectos éticos y, sobre todo, la conversación; ya que esta fue la que permitió percibir mejor el escuchar. La forma metodológica que se asumió fue la entrevista conversacional, a partir de la cual se pudo interactuar con 10 maestros de educación básica, lo que posibilitó un desarrollo narrativo que entrelazó las voces personales de los maestros, sus saberes y sus puntos de vista con las voces de los autores referenciados. Entre lo que surgió de esta investigación resaltamos el poder situar la escucha como experiencia en ámbitos escolares, el que la voz y el silencio sean componentes esenciales de una oralidad que da paso a la conversación, el que esta sea un valioso recurso que se puede asumir en el ámbito escolar para alimentar procesos de escucha y el que se pueda consolidar la relación escucha-ética.

Palabras clave: escucha, maestros, conversación, escucha ética.

Recepción: 2019-03-14

Aprobación: 2019-08-27

\begin{abstract}
From a qualitative investigation about the need for exploration around the topic of listening with basic education teachers, emerges an exploration supported by theoretical levels like voice, silence, ethical aspects and the conversation. This last one did listen perceptible through the methodological form named conversational interview, made to 10 basic education teachers. These interactions allowed to listen the voices of teachers from their wisdoms and their points of view with the voices of mentioned authors. In this investigation, we highlight the listening as experience in school environments, the voice and the silence are essential components of an orality that makes the conversation possible, and it is a valuable resource to assume in the school environment to provide listening processes. We emphasize too the possibility to reinforce the relationship between listening-ethics.
\end{abstract}

Keywords: listening, teachers, conversation, ethical listening.

* Este artículo proviene de una investigación doctoral realizada en la Universidad de La Plata (UNLP) alrededor del tema de la escucha desde entrevistas conversacionales con maestros durante los años 2017 y 2018.

1 Profesora de planta en la Facultad de Ciencias y Educación de la Universidad Distrital Francisco José de Caldas. Doctora en Ciencias de la Educación, Universidad Nacional de La Plata, Argentina. Correo electrónico: grojasa@udistrital.edu.co 


\section{Introducción}

En la conversación, la verdad es en el acto, relativa a los intérpretes presentes que sostienen la cuerda.

Manuel Canales

La indagación sobre la escucha como un tema poco abordado en el ámbito escolar permitió ahondar alrededor de las características de la escucha y la conversación desde las voces de 10 maestros formados o en ejercicio profesional en instituciones de educación pública de Bogotá (Colombia)². Se determinaron previamente varios planos teórico-conceptuales desde la voz, el silencio, la conversación y algunos aspectos éticos que permitieron llegar a que la mejor estrategia metodológica tenía que ver con la conversación, dándole consistencia a la relación epistemológica y metodológica (Vasilachis, 2006).

Siendo la investigación de corte cualitativo-narrativo se asumió la conversación más allá de ser una mera tipología discursiva o un objeto de estudio per se, porque la intención fue resaltar el lazo intersubjetivo que ofrecía el escuchar a los maestros desde una forma conversacional, que se relacionó metodológicamente con la entrevista, de acuerdo con las características validadas por Valles:

[...] en las conversaciones normales, las preguntas y respuestas se encadenan de modo similar a las tomas de palabra en la conversación, decidiendo sobre la marcha [...] se subraya la necesidad que tiene el investigador de conocer los sobreentendidos, el vocabulario propio de la gente, los símbolos y metáforas con que describen el mundo. Algo que está en la base de cualquier conversación. (2002, p. 39)

A lo anterior se le suma la perspectiva de Canales (2002), quien, respecto a la conversación, va a

2 El uso genérico masculino se emplea en el presente trabajo para referirse a ambos sexos por economía del lenguaje, para evitar dificultades sintácticas y de concordancia, así como evitar complicaciones innecesarias de redacción y, sobre todo, para facilitar la lectura del texto (cf. RAE, 2018; Bolaños, 2013; Abad-Faciolince, 2006; Hoyos-Ragel, 2002). Se hace necesario decir, además, que los maestros con los que se conversó también usaron el uso genérico masculino en la mayoría de sus intervenciones. Este uso genérico aludido no implica desconocer los esfuerzos que se dan a nivel mundial en todo lo que atañe al uso de un lenguaje no sexista y, sobre todo, a una reivindicación de derechos que mi condición y mi acción de ser mujer no desconoce. decir que no solo se puede hablar, sino que tal vez lo más potente sea que se puede "hablar de lo que se escucha [...] sobre la reversión del paso habla/ escucha, se hace posible la reflexión que vuelve por afuera, desde un lugar anterior a lo que se venía hablando. Así, se habla de lo que se habla" (p. 34).

Así surge la forma metodológica entrevista conversacional (EC) que, dada a través de preguntas estructuradas y planificadas, a la vez deja fluir con libertad lo que se percibe, se siente y se piensa ${ }^{3}$. En el juego de voces que surge a través de la EC la escucha es lo que se ofrece y lo que se quiere sostener; en concordancia con las ideas de Portelli (2018) y de Skliar (2015), para quienes no es que hay que darles voz a los que ya la tienen, sino ir y escuchar esas voces donde ya están.

Esto llevó a que se reflejara la voz escuchada de los maestros en el mismo nivel y en igualdad de condiciones de los autores mismos que sustentaron el trabajo, ya que la narrativa que surgió desde la EC planteó no solo un conocimiento, sino, sobre todo, la singularidad de cada maestro, realzando su voz (la que, a su vez, confluía, se cruzaba y se entremezclaba con la de los autores citados y referenciados).

En este artículo acudimos preferentemente a ilustrar algunos aspectos y características de la escucha que percibieron y narraron los maestros a partir de su formación y experiencia escolar a través de la respectiva EC que se sostuvo con cada uno de los involucrados. Esto incidió en que la EC fuera no solo una estrategia metodológica de investigación, sino un móvil para reflexionar y trascender alrededor de la conversación como interacción que puede alimentar procesos de escucha en entornos escolares y que traza consideraciones para una escucha ética.

\section{El escuchar de los maestros}

Ante todo, es necesario tener en cuenta que la escucha ha sido uno de los procesos más relegados en muchas disciplinas, teorías, investigaciones y

3 Se utiliza la sigla EC para referirnos a entrevista conversacional. Así mismo, de acuerdo con el orden sucesivo en que aparecen se van referenciando como Ec1, Ec2, Ec3... etc. En este artículo aparecen referencias a $8 \mathrm{EC}$, por cuestiones de pertinencia y espacio. Se puede acceder a todos los lineamientos y especificidades de las ECS, así como a todas las transcripciones en: https://bit.ly/3ckVZ2o 
prácticas de enseñanza, tal como lo señalan Murillo (2009), Aguilar (2010), Cassany et al. (1994) o Rojas (2017), entre otros. Vemos que desde los clásicos griegos que cimentaron las bases del pensamiento occidental se le ha dado amplia relevancia a la expresión oral y al habla, así como la voz desde la palabra hablada es la que primero se convoca para generar atención (Lenkersdorf, 2008).

Así, una de las dificultades o falencias percibidas en el ámbito escolar es que no hay una cultura de la escucha y esta no ha sido valorada en su justa dimensión. La escucha simplemente se ha supuesto y se ha pasado por alto. Si bien se nos enseña primero que todo a leer y a escribir, poco o casi nada se enseña a escuchar, a pesar de ser un proceso que se exige casi todo el tiempo como sinónimo de callar en las aulas escolares (Cassany et al., 1994; Gutiérrez, 2017; Murillo, 2009)².

Desde la investigación que tuvo en cuenta las voces de maestros emergió lo planteado por alguien como la maestra R. R. (Ec3), quien dijo que hay un arraigo en la escuela a solo escuchar para seguir normas en los más pequeños porque en esta se ha enseñado a seguir instrucciones y a obedecer, pero no a escuchar y no a escucharse a sí mismos:

[...] los más pequeños son los menos escuchados [...] solamente obedecer, realizar instrucciones y ya $\mathrm{a}^{5}$.

Esta obediencia cobra el sentido de mandar callar por parte de quien tiene el control de grupo para que se preste atención. Este es un tema que viene desde tiempo atrás en el mundo escolar, como lo dice también el maestro J. D. M. (Ec5):

[...] siempre nos enseñaron usted haga caso y no pregunte $[\ldots]$ nos enseñaron a recibir las órdenes, a

4 A pesar de esto, es de anotar que así como las fronteras investigativas se han abierto para la oralidad en los últimos años (Gutiérrez, 2017), también se han abierto para la escucha, cuya búsqueda y producción investigativa también se ha incrementado (León, 2019; Motta, 2018).

5 Los contactos con los maestros se establecieron con egresados de la Licenciatura en Humanidades y Lengua Castellana de la Facultad de Ciencias y Educación de la Universidad Distrital Francisco José de Caldas y con profesores vinculados a instituciones adscritas a la Secretaría de Educación de Bogotá. Para mayor detalle sobre términos y condiciones de las ECS, así como para acceder al instrumento utilizado, véase el enlace antes referenciado. obedecer, pero [...] a no cuestionarlas [...] generalmente, el niño escucha al adulto [...] eso es lo que más pasa. El papá siempre les habla a los niños: "usted escúcheme", "usted hágame caso", "usted no me pregunte", "usted no me cuestione", y la escuela históricamente ha sido eso [...] el niño [...] tenía que hacer caso todo el tiempo [...] no nos enseñaron a escuchar [...].

Esta mirada de cumplimiento y sometimiento, que es la tradicional cuando se habla de obedecer, no implica la profunda relación que tiene la palabra en mención con la escucha, como lo sustentan desde lo etimológico Dolar (2007) y Blanco y Sierra (2015). A lo que se le puede sumar la perspectiva lingüístico-antropológica de Lenkersdorf (2008), quien vería a la obediencia más bien en consonancia con el atender y el estar presentes en el escuchar, siendo este un acto de deseo, voluntad y disposición.

Esto resulta contrario a lo que muchas veces sucede en el aula y en las prácticas escolares, en las que no todos los maestros escuchan a sus estudiantes, siendo este asunto una queja constante; en especial por parte de los niños y jóvenes, como se puede percibir desde Pennac (2008) y los maestros involucrados en las EC (R. R., Ec3; Y. M., Ec4; J. D. M., Ec5, entre otros).

Los adultos muchas veces piensan que lo que los niños dicen es vano y carece de importancia, negándose a escucharlos y suponiendo que sus opiniones son infantilismos y trivializaciones; como lo menciona la maestra T. V. (Ec1). De otro lado, el maestro J. D. M. (Ec5), quien cuestiona y reconoce que muchas veces la actitud de ellos como docentes hacia los niños pequeños en los entornos escolares difícilmente es de escucha:

[...] porque estamos acostumbrados a que no tienen mucho qué decirnos. (Ec5)

Siendo la escucha una interacción bidireccional de doble vía, como lo dicen Lenkersdorf (2008) y Gutiérrez (2017), así como J. D. M. (Ec5), se requiere de una dinámica en la que el estudiante participa activamente y hay una escucha puesta en juego que señala un avance de lo que se está diciendo, 
dando rumbo a un entendimiento conjunto (Gadamer, 1998). Lo que muestra que el escuchar también implica por parte del maestro de por sí el ser escuchado por el estudiante en un acto recíproco que involucra las palabras, las voces y los cuerpos:

[...] da satisfacción saber que te escuchan, que te están atendiendo en muchas situaciones y que hay un proceso recíproco de escucha. (R. R., Ec3)

Para la maestra A. V. (Ec6) sí ha sido posible escuchar a los estudiantes, lo que le ha permitido inclinar su currículo, cuando ha sido necesario, a los temas que les interesan a los niños; a quienes estimula a leer, a participar, a intervenir, además de asimilar y validar la palabra misma del maestro. Rasgo compartido por T. V. (Ec1), quien señala que el escuchar a los niños obra en beneficio del maestro y valida el que aquellos escuchen, ya que

Ellos se sienten incluidos, se sienten reconocidos al ser escuchados. Y para mí, igual [...] Uno habla muchas cosas en un salón de clases y con el tiempo en las interacciones [y] en los comentarios que ellos hacen, uno se da cuenta que ese comentario está constituido a partir de lo que yo [como maestra] en algún momento les llego a decir [...] algo de lo que yo digo, ellos lo escucharon y lo asumen ahora y lo expresan [...] me escucharon en algún momento lo que yo dije, y ahora es su voz la que lo está expresando porque sintieron que está bien [...] y ahora lo tienen en cuenta.

Entonces, el acto de la escucha sí puede ser posible en la escuela como experiencia real que se aprende y que es viable alimentar. Como lo explica R. R. (Ec3) aludiendo a algunos profesores que la formaron como maestra:

[...] en esa calidez y ese amor por su profesión y por los niños, también tenían esos momentos de escucha con ellos, tenían esos momentos en donde se sentaban y escuchaban y conocían esos niños.

Esto ha llevado a la maestra en mención a ejercer su profesión sabiendo de antemano que "realmente es importante escuchar así sea al más pequeño o al más grande", y a que en su experiencia
[...] es fundamental escuchar a los niños, no escucharlos solamente en cómo es ese proceso de aprendizaje y de evaluación frente a si aprendió o no aprendió, sino más escucharlos en su vida diaria, en su cotidianidad. He tenido muchos asuntos, digamos, particulares con los niños en donde he logrado descubrir, no solamente la escucha [de ellos] sino también a sus propias familias [...].

En este panorama no se puede pasar por alto que esta es una de las épocas en las que los niños y jóvenes se desbordan en su discurso en el ámbito escolar, ya que nunca habían hablado tanto como en los tiempos contemporáneos. Desde la antigüedad griega hasta la Europa moderna, estaba proscrito el que el niño hablara libremente del sistema educativo, según Foucault (2002). Que los niños deben guardar silencio antes de hablar, "es un principio que nos sorprende en esta época, pero no hay que olvidar que hace sólo unas decenas de años la educación de un niño [...] comenzaba en lo fundamental por el aprendizaje del silencio" (p. 326).

También Chambers (2007) señala que anteriormente los niños podían ser vistos, pero no oídos y hoy: "se critica a los adultos por no escuchar lo suficiente a los niños, que son estimulados dentro y fuera de la escuela para que expresen sus ideas" (p. 11). En tiempos actuales se les exige participar más que nunca y la expresión oral de ellos cobra una importancia inusitada que antes no se tenía en cuenta.

A pesar de lo dicho, siguen existiendo por diferentes factores aquellos niños silenciosos, callados, tímidos, casi mudos de los cuales, muchas veces, no se conoce ni se reconoce su voz ni lo que piensan. Ante esto, T.V. (Ec1) planteó el tipo de acercamiento que hace con ellos:

[...] uno ya reconoce quién es el que habla y quién es el que no habla. Entonces generalmente, cuando estamos en ese tipo de conversaciones, yo dirijo preguntas [...] a ellos directamente, a los que casi no hablan. Me he cuestionado [...] por qué los chicos se paralizan, no saben qué decir en muchas ocasiones, ni siquiera me responden, se quedan callados y ya. Entonces yo [...] dinamizo la conversación hacia otro lado, la clase hacia otro lado, pero sí intentando 
[...] integrarlos, a partir de preguntas dirigidas específicamente a ellos, y también [...] con mi voz, darles seguridad, y al integrarlos a la conversación ser muy asertiva en afirmar que lo que ellos dicen y piensan está bien. Siento que es darles esa seguridad, porque muchos chicos que no participan [...] piensan que lo que dicen está mal, que se van a burlar de ellos. Entonces ahí el papel del profe es muy de darles ese piso [...] para que ellos se sientan muy seguros.

En esa posibilidad de escucha está implícito algo más allá de lo cognitivo, del intelecto y los procesos de aprendizaje y enseñanza. Está la observación ligada a la escucha de actitudes y comportamientos que generan la expresión de los niños en:

[...] contextos en los que ellos pueden hablar un poco más desde lo que realmente son y quieren ser o de lo que nos ocurre a diario. (R.R., Ec3)

Por ello, la escucha se hace extensiva a la observación y percepción de gestos, de miradas, de actos, de actitudes, de lo proxémico; de aquello que se escucha (aunque no sea audible) y que lleva de una semiótica de la escucha a una escucha de lo que no se oye.

\section{La escucha de lo inaudible}

La mayoría de la comunicación es no verbal y demuestra que la escucha es un proceso activo, que requiere de atención no solo a través de lo audible, sino también mediante el contacto visual. La observación paralingüística lleva a prestar cuidado sobre los sonidos no verbales, los silencios, las pausas, el tono de la voz o las posturas corporales (Valles, 2002; Echeverría, 2005). Este tipo de elementos no enunciados oralmente son necesarios de ser observados, sobre todo, cuando se trabaja con aquellos niños que aún no manejan la expresión oral de forma clara y para quienes son dicientes las intenciones, las miradas, el manejo de las manos y toda la conciencia corporal que necesita ser percibida por un docente. Como expresa J. D. M. (Ec5):

[...]nosotros no solo hablamos con la palabra audible, sino que nuestro cuerpo habla, la forma en que miramos habla, tenemos un sistema de lenguaje kinésico [y] proxémico también, que todo el tiempo comunica algo.

Esto a su vez implica que el escuchar y la observación vayan de la mano y que el maestro requiera una escucha que vaya más allá de lo oral, de lo audible, que atraviese y descifre lo no verbal, lo gestual, las actitudes y aquello que no tiene una representación en las palabras. Ya que un niño siempre manifiesta verbal y no verbalmente lo que piensa, el maestro puede ser alguien dotado de alta percepción sobre los indicios lingüísticos y paralingüísticos que tiene una gran capacidad de escuchar y de observar, la que se puede desarrollar, como lo dice J. D. M. (Ec5):

[...] en la medida en que los niños y las niñas realmente [te] importan.

Según R. R. (Ec3), la escucha de lo no audible también implica comunicación en el contexto en el que el movimiento, el cuerpo y lo que no dice la voz representan actos y comportamientos. Por ende, el tema del cuerpo y de la corporalidad necesita incluirse en todas las clases porque alimenta diferentes niveles o complejidades en el lenguaje, expresión y comportamiento de los niños, dice la maestra en mención.

Lo paralingüístico, lo no enunciado, lo que dicen los gestos, las miradas, las posturas y en general, el lenguaje del cuerpo, definitivamente no pueden escapar a la voz y a la escucha, se convierten en partes difusoras de mensajes que muchas veces son más dicientes que lo enunciado (Le Breton, 2006; Ong, 1987; Mancovsky, 2011). Como dice L. P. (Ec7) uno habla con todo el cuerpo y en ese sentido puede representar también brusquedad, agresividad; se puede gritar a través de las manos, de los gestos, de las posiciones, de las distancias, de las miradas que retan, que discriminan y que muchas veces enuncian más, que las mismas palabras como si fueran "gritos sordos" (Y. M., Ec4). Lo que también pueden aturdir y cortar la comunicación:

[...] tengo mi voz tan suave [...] mis estudiantes me comentan, "profe es que usted no nos lo dice 
con su voz, nos lo dice con su gesto, con la expresión de su cara". Entonces también es eso, como las expresiones del rostro a veces son más notables, son más dicientes que la misma voz, la voz que aterriza, la voz que distancia, la voz que grita, aturde, corta la comunicación, [...] Para ellos, que yo grite es que suba un poco más el tono de mi voz, entonces realmente en mis clases no se siente, o no utilizó ese tipo de estrategias, pero sí utilizo aquellas que tienen que ver con el cuerpo [...] creería que la mirada fija, que el mismo silencio, el mismo callarse [son formas] de demostrarle a los estudiantes otro tipo de inconformismo por el comportamiento de ellos, que el mismo grito. (Y. M., Ec4).

Con todo lo anterior, vemos que hay cosas que son imposibles de decir, pero esto no impide que también se puedan escuchar, observar y percibir. Por lo general, prima lo que conduce a una escucha de lo audible, porque la predominancia está en lo que emite la voz, aquella que siempre será a la que la escucha se doblegará con mayor intensidad. Esta, como vemos, indefectiblemente requiere de observación de señales, gestos, distancias, actitudes que van más allá de la voz o de lo lingüístico.

Por otro lado, aunque usualmente se ha concebido a la escucha como un proceso pasivo, se ve que se da al hablar o al expresarse $y$, siendo estos procesos indisociables, también se da una mutua alimentación y actividad entre quien habla y quien escucha. Por ello, resaltamos a la oralidad como el proceso que determina la escucha (Gutiérrez y Uribe, 2015), en el que esta no tiene un papel pasivo ni silencioso; al contrario, puede ser muy activo: "colabora en la conversación [...] Da a entender al que habla, de una u otra forma, que sigue y comprende su discurso [...] ¿Es posible hacer entender algo a alguien que no muestra ningún interés en escuchar [...]?" (Cassany et al., 1994, p. 102).

En ese sentido, se trata de estar presentes, aunque el solo hecho de la presencia no implica que se esté escuchando, ya que también "puede suponer indiferencia si refleja una actitud ausente o rutinaria que concede a la palabra un valor residual o nulo" (Le Breton, 2006, p. 56). La escucha entonces, no es un ejercicio solo de callar y sirve para comprender:

[...] que hay otro que me está diciendo algo y que es necesario escucharlo para yo también aprender [...] entender que es lo que siente el otro para decirme y hasta qué punto estoy yo también dispuesto a escuchar. (Y. M., Ec4)

En esto, también confluye lo que postula Lenkersdorf (2008): "Se presuponen al menos dos personas para referirse al hablar y al escuchar. Ninguna de las dos es más importante que la otra. Sin hablar no se escucha nada, y sin escuchar se habla al vacío" (p. 59). Lo que también fluye en la misma línea en que T. V (Ec1) expresa:

[...] lo más importante es reconocer que no estamos solos y que lo que yo soy es un cúmulo de cosas que constantemente estoy escuchando, seleccionando, significando y vuelvo y las expreso.

Este ejercicio es posible a través de la conversación, que puede determinar un equilibrio entre la voz y la escucha, ya que lo que permite escuchar es que se sabe de antemano que también se tendrá su turno, que en algún momento se hablará, se participará o se interactuará. Si no se tuviera garantizado esto previamente, tal vez no se escucharía en ninguna circunstancia, como se puede inferir desde Cassany et al. (1994), Lenkersdorf (2008), Echeverría (2005), Gadamer (1998), Portelli (2018) y Marco-Furrasola (1999); este último dice al respecto: "[...] el ser humano no ha nacido para ser una gran oreja. El hombre encuentra el equilibrio interaccional en el intercambio" (p. 100).

\section{Conversación para la escucha en el ámbito escolar}

La conversación suele darse entre un grupo restringido de personas. Vale recordar a Montaigne (1953), quien asume que la conversación únicamente puede darse entre contadas personas: "Me gusta contestar y discurrir, pero es con pocos hombres y en 
privado" (p. 299). Este número restringido entre quienes participan en una conversación es también planteado por Gadamer (1998), por Kerbrat Orechionni (cit. en Calsamiglia y Tusón, 2002) y por Pava-Ripoll (2015), ya que el número limitado de participantes hace que la conversación fluya y que todos los integrantes intervengan en ella. Sin embargo, no hay un número ideal de personas para participar en una conversación.

En un ámbito como el escolar concretamente, una de las quejas frecuentes de los maestros es la cantidad de estudiantes que se tienen en un aula y que les impide mantener una conversación, porque es muy difícil escucharlos a todos y muchas voces se pierden por esa dificultad, ya que las dinámicas y los tiempos escolares no son fáciles:

[...] las voces de todos los niños, no se logra [...] escucharlas realmente [...]. Desafortunadamente, en los contextos que nos movemos generalmente es con muchos niños, entonces a veces tienes un grupo de 40 niños, de 30, de 35, y a veces, realmente llegar a escuchar a todos [...] la verdad es muy esporádico.

(J. D. M., Ec5)

Sin embargo, la participación y las preguntas de los estudiantes pueden constituirse en un indicador de que la interacción fluye, que el estudiante se interesa y quiere seguir con el tema. Si el profesor da cuenta de ello la escucha se activa teniendo conexión con implicaciones narrativas porque a los niños les gustan las experiencias de vida, lo anecdótico, el que se les cuente historias, cualquier conocimiento que sea contextualizado (J. D. M., Ec5).

En estos ejercicios de conversación la voz del maestro fluye con la de los estudiantes, pero teniendo en cuenta que hay niños a los que les gusta hablar y participar y hay otros a los que no, la actitud de conversación del maestro es la que propicia que los niños más tímidos participen y sus voces puedan ser escuchadas, creándose una atmósfera de interacción conversacional (A. G, Ec10; T. V., Ec1).

Esto puede ayudar a sensibilizar al maestro para percibir actitudes y comportamientos del niño, ya que la escucha es algo que atraviesa todas las áreas, y a través de ella se pueden solucionar muchas situaciones de convivencia en el aula, dándoles:

[...] la posibilidad a los niños cuando más lo necesitan contar diferentes experiencias, de hablar de lo que les ocurre y de porqué esas situaciones inciden muchísimo también en su comportamiento o en el aula misma. (R. R., Ec3)

Así, la conversación se sale de los cánones establecidos en un aula de clases cerrada en la que la voz del maestro es la que dirige, coordina, establece, pero no escucha. Las dinámicas que exigen interacciones más vitales que generen actitudes conversacionales pueden darse incluso con los estudiantes más chicos, aunque esto requiere un cambio de postura frente a la mirada que tenemos sobre la infancia o sobre los niños como aquellos a quienes enseñamos como seres carentes, a los que les falta algo, que siempre necesitan aprender, como lo dice el maestro J. D. M. (Ec5):

A veces en esos espacios informales es donde más se aprende [...] cuando uno se sale un poco de lo formal [...] cuando uno como educador, va y se sienta con los chicos [...] ese es el momento cuando más tiene uno posibilidad de conocerlos [...]. Es el momento cuando más tiene uno oportunidad de contarles otras cosas que les aportan, fuera de lo formal, del área que estén trabajando [...] del contenido escolar. [...] cuando uno habla con ellos de una manera informal es [...] cuando más le aportan a uno y donde se genera una conversación [...] si trabajáramos más con lo que ellos ya tienen y no con lo que les hace falta [...] cualquier niño o niña, sin importar la edad, así sea de nivel inicial, sea el más chico [puede dar cuenta que] tiene una construcción cultural que ha venido formando. (Ec5)

La riqueza de la conversación, como dice el maestro L. P. (Ec7), se da:

[...] cuando justamente lo que dice el otro te transforma [...]. Cuando hay una trasformación de lo que está pasando [...]. Hay una verdadera conversación cuando hay una verdadera experiencia. 
En esa medida, la relación educativa es experiencia que se abre a la escucha de lo que nos sucede y lo que nos significa donde la relación de intercambio (la conversación) es abierta a la escucha del otro para construir el encuentro (Contreras y Pérez, 2011)6.

Pero también es indudable que es difícil instalar la conversación en estos términos en la escuela, ya que hoy en día lo educativo está radicalmente centrado en lo evaluativo y esto cierra los espacios para la conversación, que va más allá de juegos arquetípicos y experimentales, ligados a mecanicismos de preguntas y respuestas $y$, sobre todo, a actividades de orden evaluativo, que poco o nada avanzan en esa interacción de conversación y escucha entre maestro-estudiante que en tantos escenarios escolares necesita ser transformada.

Aunque las experiencias de algunos maestros con los que se conversó muestran que sí hay conversación con sus estudiantes, también se muestra que esta no aflora porque no se puede evaluar o porque no es compatible con los términos de evaluación que tanto busca el entorno escolar. Pareciera que los espacios escolares no son ámbitos en los cuales se da la conversación, precisamente porque es resbaladiza a la evaluación:

[...] la conversación [...] no tiene mucha cabida en el ámbito educativo [...] porque normalmente lo que se ve es un monólogo en que el estudiante llega, se para y habla. Y así mismo, el maestro [...] ya saca sus notas porque desafortunadamente, el tema de la evaluación y de la nota tiene demasiado peso. (R. R., Ec3)

Cuando se condiciona el aprendizaje a la nota, este se vuelve ficticio, algo falso, algo que no repercute en las subjetividades de los estudiantes:

[...] el niño estudia en la casa, pero no porque quiera aprender sino por una nota. (A. V. Ec6)

6 Sobre la relación de escucha como experiencia vale la pena tener en cuenta a Foucault (2002), quien señala que para escuchar como corresponde "precisamos la empeiria (la habilidad adquirida) y la tribe (la práctica asidua), así como para hablar se necesita una tekhne" (p. 323). La escucha lo que más requiere es "experiencia, competencia, práctica asidua, atención, aplicación [...] Empeiria y tribe [...] no tekhne" (p. 324).
Así emerge la pregunta: ¿es más fácil para los niños conversar porque no hay evaluación?, a lo que T. V. (Ec1), dice:

Yo sí siento que a veces la evaluación coarta la conversación [...] porque eso puede de cierta medida, modelar las respuestas, intenciones de las personas que estén participando [...] porque si yo propongo un debate sobre un libro $[. .$.$] y [. .$.$] esa$ dinámica de grupo es evaluable [...] los chicos [pueden pensar] que, si se salen del protocolo que tiene la dinámica, su nota puede variar.

Entonces, en la conversación más que un profesor que explica emerge la figura de alguien que conoce sus límites y sus fragilidades que, en esencia, es lo que permite escuchar (y aprender). Desde esa unidad valdría la pena replantearse cómo reconstruir tanto el enseñar como el aprender para así hacer inevitable la conversación en una atmósfera de igualdad inicial en donde se pueda escuchar a todos, a cualquiera y a quien sea (Skliar, 2017).

Muchos de los asuntos que para los niños son un problema y que muchas veces el maestro no tiene en cuenta implican caminos que pueden desentrañarse en el conversar, ya que ayudarían a plantear una manera de entender el mundo y la vida. Como lo señala la maestra A. V. (Ec6), para quien:

[...] hay que tener en cuenta cómo siente el niño, cómo está viviendo en la casa, cómo son las relaciones con la familia.

Ya que para ella educar sí debe ser un acto de conversación con el otro, porque muchos de los problemas que surgen entre los maestros y sus estudiantes, tienen que ver con que el maestro le falta tiempo para conversar. Por ello, es necesario que el salón de clase sea un espacio de conocer más al otro, y que no todo este abocado a querer solamente resultados tal como lo plantea no solo A.V. (Ec6), sino Skliar (2017) o Meirieu (1998).

Aunque es usual en las aulas que no dure mucho la conversación entre estudiantes y maestros, esta sí puede darse, de acuerdo con cierto tipo de palabras utilizadas, miradas, gestos, expresión de 
las manos, de la cara, de todo cuerpo, de todo lo que produce recepción y hace que se invite al niño a la conversación (Y. M., Ec4; Chambers, 2007). Pero hay que estar abiertos a no solo ver los temas y a trabajar las actividades curriculares preestablecidas, porque según la maestra A. V. (Ec6) a los niños lo que más les interesa es entender la vida en sí, más que el contenido curricular y:

[...] la conversación definitivamente es como una meta, poder escuchar a los niños [...] escuchar al otro y no [solo] lo que yo diga [como maestra]. (Ec6)

Es posible, entonces, incorporar la conversación en las prácticas educativas desde una concepción ligada al conocimiento donde los mismos maestros la impulsen como si fuera parte de la interacción entre docente y estudiante para que se genere una escucha más auténtica, como lo dice la maestra P. F. (Ec8):

[...] de pronto el meollo de la cosa, la esencia del encuentro con los niños y despertar interés por el conocimiento, es la conversación [en sí].

Vemos que un maestro puede ser muy ilustrado en todos los discursos acerca de la infancia, pero no ser capaz de conversar con los niños, lo que plantea una especie de incongruencia, ya que cuando un maestro no es capaz de conversar con ellos hay un impedimento para pensar y compartir lo educativo en sí (Skliar y Téllez, 2017). La conversación es la posibilidad de ser la primera y más honesta tarea de un maestro, aquella que implicaría escuchar y aprender de los niños.

Conversar para educar es una deuda que tenemos en los ámbitos escolares, aunque esta dificultad vaya más allá de las fronteras de la escuela:

[...] ya casi no se conversa con los otros, ya no se conversa de otras cosas; en el mejor de los casos sólo se conversa siempre entre los mismos y siempre de las mismas cosas. El lenguaje se ha vuelto un refugio opaco de narrativas sombrías donde cada uno repite para sí y se jacta indefinidamente de sus pocas palabras, de su poca expresividad y de su incapacidad manifiesta para la escucha del lenguaje de los demás. Casi nadie reconoce voces cuyo origen no le sean propias, casi nadie escucha sino el eco de sus propias palabras, casi nadie encarna la huella que dejan otras palabras, otros sonidos, otros gestos, otros rostros. (Skliar, 2011, p. 142)

Aunque hay algunos trabajos, propuestas, experiencias e investigaciones educativas y didácticas alrededor del conversar y del escuchar (Mercer, 1997; Chambers, 2007; Rojas, 2015; Beuchat, 1989; Cassany et al., 1994); sigue siendo el espacio escolar uno de los entornos en el que más se reclama el escuchar con relación al callar para entregarse a la voz de aquel que representa mayor autoridad, lo cual muestra una perspectiva muy reduccionista de la escucha y la conversación tal como se puede confrontar con lo dicho por los maestros (R. R., Ec3; T. V., Ec1; J. D. M., Ec5).

Por lo anterior, en la escucha desde la conversación emerge una relación ética por excelencia de la cual no nos podemos desligar porque implica al otro en sí mismo y la alteridad que deja expuesta la diferencia y la singularidad del otro. Aunque no nos corresponde en este espacio abordar el tema de la ética tan de largo alcance como es, esbozamos algunas ideas en la búsqueda de una escucha ética.

\section{Hacia una escucha ética en la escuela: una reflexión pendiente}

Escuchar es un gesto ético por excelencia. Escuchar al otro, independientemente de su condición o de quién sea, encarna lo ético. Por esto, se escucha no para entender al otro, sino para entender con el otro, acogiéndolo en su necesidad de decir algo y recibir las palabras albergadas por alguien. La reciprocidad de la ética con la escucha ha sido planteada por Arenas-Dolz (2014), Cepeda (2012) y Aranguren (2008), entre algunos. De modo que es necesario ahondarla en el terreno de lo educativo, donde lo que se establece entre un maestro y un

7 En ese sentido, Gadamer (1998) va a señalar que quien no escucha es "aquel que permanentemente se escucha a sí mismo, aquel cuyo oído está [...] tan lleno de aliento que constantemente se infunde a sí mismo al seguir sus impulsos e intereses" (p. 209), por lo que no es capaz de escuchar al otro. 
estudiante implica una relación que, ante todo, es inevitable nominarla como ética.

Sin embargo, la indiferencia ante la escucha por parte de algunos maestros, pareciera querer decir, según J. D. M. (Ec5): “igual a mí me pagan escuche o no escuche", lo que acarrea que puede primar más el llevar a cabo un programa académico preestablecido que detenerse a escuchar a los estudiantes porque lo que se necesita es avanzar, se necesitan los resultados que demuestran las evaluaciones, como lo dicen R. R. (Ec3) o A. V. (Ec6).

Por eso, pareciera que los estudiantes hoy en día entienden y aceptan que ser enseñados es ser evaluados y ese resulta ser el punto más fuerte de lo educativo para ellos. Esto hace que lo que solo busca evaluarlo todo como si ello fuera el fin de lo educativo en sí mismo, lleva a que se pervierta el sentido del enseñar y del aprender, que no pueden ser sinónimos de evaluación, como se está entendiendo hoy en día.

La evaluación se ha convertido en el mayor motivo de preocupación en la escuela, rebajando el interés por enseñar a la premura del tiempo solo para juzgar permanentemente al otro; no para estar, pensar, jugar, conversar o escuchar con el otro, sino por el afán de evaluación que sobreviene en norma. El caso contrario es que estemos atentos y disponibles ante el otro, porque el tiempo que escucha no es el tiempo que juzga o evalúa (Skliar, 2017).

Por eso la escucha muchas veces escapa a la escuela, porque la escucha es dar tiempo sin prever qué tipo de resultados devengan ya que, si solamente tenemos tiempo para juzgar, para evaluar y para buscar resultados, al maestro nunca le va a quedar tiempo para conversar. La ética y la evaluación parecen estar en caminos opuestos, lo ético no puede ser un proceso de medición (Skliar, 2017; L. P., Ec7).

Dentro del plano escolar, una escucha ética se movilizaría, sobre todo, entre los niños y sus maestros como uno de los ejercicios de alteridad más característicos en el que se reconoce a los estudiantes sin homogeneizarlos, etiquetarlos o estigmatizarlos (R. R., Ec1; Y. M., Ec4). Uno de los elementos que impiden, quizás, que haya conversación y escucha ética en la escuela, especialmente entre docentes y estudiantes, es la discriminación, la tendencia constante a juzgar, desde una posición de exclusión que impide dar a conocer los argumentos, posiciones o visiones de mundo del otro. Lo que imposibilita la escucha y la conversación entre un maestro y un niño (sobre todo, el que no es buen estudiante o el que presenta un comportamiento y una conducta inadecuada para los cánones profesorales), es esa tendencia a rotularlo, a catalogarlo o a cerrarse a escucharlo, porque lo que este tipo de niño diga no entra, no conecta con el maestro, y cualquier conversación queda interrumpida de antemano (J. D. M., Ec5).

Si la escuela:

[...] no es una institución que escucha [porque] la gente nunca se da a la tarea de escuchar verdaderamente a los otros, sino que ya tiene de antemano sus propias respuestas. (L. P., Ec7),

el no escuchar es uno de los cuestionamientos más recurrentes cuando de irrespeto se trata:

[a] los niños [...] les duele mucho cuando un maestro no los escucha, o los critica bastante, entonces ellos cierran la comunicación [...] el niño lo único que quiere es que lo escuchen. (A. V., Ec6)

Asumir el silencio como condición para la escucha es un imperativo ético para la afirmación y el reconocimiento del otro (Plutarco, 1995; Lenkersdorf, 2008). Postura que se hace necesaria en el escenario escolar más allá de acallar al otro para que se escuche la voz de quien tiene más peso o autoridad. De lo que se trata más bien es de aquietar el impulso inmediato que muchas veces implica hablar, dando paso a esa indiscutible atención que requiere el otro sin importar su condición.

Ser receptor de las palabras escuchadas es confiar en el otro e implica esa condición milenaria en la que solo se podía ser autoridad (seleccionada) si se sabía escuchar (Lenkersdorf, 2008): "alguien nos escoge, nos encuentra y habla con nosotros. Somos como elegidos para escuchar" (p. 59). También escuchar acercándonos al otro y recibiendo de él las palabras que nos ofrece sin prejuicio alguno es una de las premisas fundamentales de la hospitalidad (Skliar, 2017). Por esto, se debería enfatizar más el 
escuchar que el hablar, porque el recibir palabras (escuchar) es sentirse obsequiado y toda la atención debe estar puesta en el otro (Lenkersdorf, 2008), lo que nos hace ver que "escuchando al otro se abre el verdadero camino en el que se forma la solidaridad" (Gadamer, cit. en Larrosa, 2003, p. 94).

La conversación en la escuela puede darse desde los propios saberes, posiciones y observaciones de los niños y los jóvenes, sin que medie de antemano un interés evaluativo (que obligue a la entrega, al devolver o al retribuir un conocimiento como el maestro lo quiera evaluar), panorama en el que el maestro podría ser una figura de generosidad que se base en actos de ofrecimiento, de dar, de donar (tiempo, conversación, escucha...); y no en actos de imposición en los cuales la mezquindad que implica estar requiriendo lo aprendido para ser evaluado cierra la interacción conversacional.

Se trata de recibir al otro sin cuestionarlo, sin preguntarle, sin sospechar de él y, sobre todo, sin juzgarlo. Para que se pueda entablar una conversación que, en lo posible, lleve a los temas fundamentales de la existencia, porque abrirnos al otro implica que de una vez por todas se permita una conversación y una escucha (asunto ético por excelencia), ligada a la posibilidad de que un maestro en una atmósfera inicial igualitaria admita que todos pueden tomar y tener la palabra de alguna manera, libres de cualquier interacción experimental o de control evaluativo (Meirieu, 1998; Skliar, 2017).

Buscar la propia voz a través de la voz de los otros implica indagar por medio de la escucha de los otros nuestra propia escucha. Aquella que basada en sentir, percibir y experimentar al otro nos Ileva a la conversación y a la huella por excelencia de la comunión: al nosotros.

\section{Referencias}

Abad-Faciolince, H. (19 de agosto de 2006). Colombianos y colombianas, ¿ridículos y ridículas? Semana.

Aguilar, M. (2010). ¿Qué significa escuchar? Carta Psicoanalítica, 4. http://www.cartapsi.org/new/ que-significa-escuchar/

Arenas-Dolz, F. (ed.) (2014). Éticas de la escucha. Reproexpres.
Blanco, N. y Sierra, E. (marzo de 2015). Aprender a escuchar. Cultivar la disponibilidad en la investigación educativa. En $V$ Jornadas de historias de vida en educación. Voces silenciadas (pp. 1-13). Universidad de Almería.

Beuchat, C. (1989). Escuchar: el punto de partida. Lectura y Vida. Revista Latinoamericana de Lectura, 3, 20-25.

Bolaños, S. (2013). Sexismo lingüístico: aproximación a un problema complejo de la lingüística contemporánea. Forma y Función, 26(1), 89-110.

Calsamiglia, H. y Tusón, A. (2002). Las cosas del decir. Ariel.

Canales, M. (2002). Conversaciones para el entendimiento. En, J. Durston y F. Miranda (comps.), Experiencias y metodología de la investigación participativa (pp. 33-39). ONU.

Cassany, D., Luna, M. y Sanz, G. (1994). Enseñar lengua. Graó.

Cepeda, M. (2012). En torno a una ética de la escucha (tesis doctoral). Universidad Nacional de Colombia, Bogotá.

Chambers, A. (2007). Dime. Los niños, la lectura y la conversación. Fondo de Cultura Económica.

Contreras, J. y Pérez de Lara, N. (2011). La experiencia y la investigación educativa. En, J. Contreras y N. Pérez de Lara (comps.), Investigar la experiencia educativa (pp. 21-86). Morata.

Dolar, M. (2007). Una voz y nada más. Manantial.

Echeverría, R. (2005). El escuchar: el lado oculto del lenguaje. En Ontología del lenguaje. Lom.

Foucault, M. (2002). La hermenéutica del sujeto. Fondo de Cultura Económica.

Gadamer, H. (1998). Verdad y método II. Sígueme.

Gutiérrez, Y. (2017). Repensar el papel del diálogo para la inclusión social, la responsabilidad política y la educación dialógica. Actualidades Pedagógicas, 69, 15-47.

Gutiérrez, Y. y Uribe, R. (2015). Cuando es posible hablar y escuchar mejor de cómo ya hablamos y escuchamos. Oralidad-es, 1(2), 192-204.

Hoyos-Ragel, M. (2002). Sexo, género y usos lingüísticos. Publicaciones de la Facultad de Educación y Humanidades del Campus de Melilla (Universidad de Granada), 32, 13-32.

Larrosa, J. (2003). Leer es traducir. Entre lenguas. En, Lenguaje y educación después de Babel. Laertes. 
Le Breton, D. (2006). El silencio. Sequitur.

Lenkersdorf, C. (2008). Aprender a escuchar. Enseñanzas mayas-tojolabales. Plaza y Valdés.

León, J. (2019). La escucha en la educación. Lenguaje, 47(2), 268-305.

Mancovsky, V. (2011). La palabra del maestro. Evaluación informal en la interacción de la clase. Paidós.

Marco-Furrasola, A. (1999). Una aproximación a la semiótica del silencio (tesis doctoral). Universidad de Barcelona, España.

Meirieu, P. (1998). Frankestein educador. Laertes.

Mercer, N. (1997). La construcción guiada del conocimiento. El habla de profesores y alumnos. Paidós.

Montaigne, M. (1953). El arte de conversar. En, Ensayos. Jackson.

Motta, J. H. (2018). La actitud de escucha en la comunicación pedagógica (tesis doctoral). Universidad Pedagógica y Tecnológica de Colombia, Tunja.

Murillo, M. (2009). La habilidad de escuchar. Una tarea pendiente en la educación costarricense. Artes y Letras, 33(2), 95-131.

Ong, W. (1987). Oralidad y escritura. Fondo de Cultura Económica.

Pava-Ripoll, N. A. (2015). Narrativas conversacionales con familias y docentes de niños y niñas con discapacidad: un aporte metodológico. Interdisciplinaria, 32(2), 203-222.

Pennac, D. (2008). Mal de escuela. Mondadori.

Portelli, A. (marzo de 2018). ¿Qué hemos aprendido? La historia oral como el arte de escuchar. Seminario del Doctorado en Historia. Universidad Nacional de La Plata.

Plutarco (1995). Sobre la charlatanería. En, Obras morales y de costumbres. Gredos.

Real Academia Española (2018). Consultas lingüísticas. Real Academia Española. http://www.rae.es/consultas/los-ciudadanos-y-las-ciudadanas-los-ninos-ylas-ninas

Rojas, G. (2017). Entre la conversación y el diálogo: algunos aspectos para la escucha. Enunciación, 22(2), 189-201.

Rojas, Y. (2015). Conversación, construcción colectiva de conocimientos y producción textual. Oralidad-es, 1(2), 179-190.

Skliar, C. (2011). La experiencia de la conversación, de la mirada y de la investigación educativa. Una desnaturalización de la incongruencia. En, J. Contreras y N. Pérez de Lara (comps.), Investigar la experiencia educativa (pp. 136-152). Morata.

Skliar, C. (2015). Desobedecer el lenguaje. Alteridad, lectura y escritura. Miño y Dávila.

Skliar, C. (2017). Pedagogías de las diferencias. Noveduc.

Skliar, C. y Téllez, M. (2017). Conmover la educación. Ensayos para una pedagogía de la diferencia. Noveduc.

Valles, M. (2002). Entrevistas cualitativas. CIS.

Vasilachis, I. (coord.) (2006). Estrategias de investigación cualitativa. Gedisa. 